\section{DNA detectivework}

\section{MarcusW. Feldman}

\author{
Reflections of $O$ ur Past \\ by John H. Relethford \\ Westview Press, Boulder, Colorado, USA \\ 320 pages, US $\$ 26$ \\ ISBN 0813339588
}

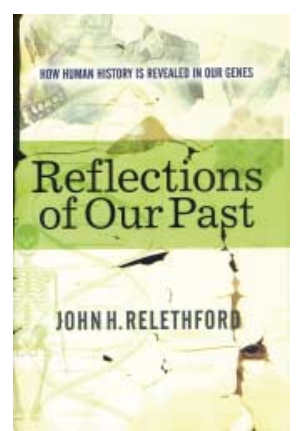

The last 15 years have seen a transformation of physical anthropology from its basis in palaeontology and archaeology, which use relatively few samples from the hominid past, to a new basis in population genetics that entails inference about the past but uses massive quantities of data from the present human populations. This transformation has been mediated by technological advances in molecular biology, which allow the data on human polymorphic variation to be revealed, and in mathematical, statistical and computational tools, which allow these data to be analysed. Although the original impetus for these advances was the deciphering of the human genome and its importance for understanding human diseases, the technological gains in producing human DNA sequences have, as a by-product, given rise to an explosion of interest in the variation of non-disease-related human DNA.

$\mathrm{Had}$ the Human Genome Diversity Project received the financial support it deserved when it was proposed in the early 1990s, the current morass of data on human DNA variation would be more systematically organized, consistent across studies, readily accessible to all researchers, and, most importantly, more representative of all human populations. The result is that, to use current human genetic variation for evolutionary inference, bits and pieces of $Y$ chromosome data, mitochondrial DNA data and, occasionally, data from the autosomes must be extracted from different sources and woven together to produce some coherence. As if to authenticate an important piece of art, the resulting genetic picture is then validated against the few dated fossils that formed the earlier basis for human evolutionary inference.
Both the genetics and the palaeontology are highly technical, and in Reflections of $\mathrm{O}$ ur Past John H. Relethford has done an admirable job of making these subjects accessible to non-experts. The book is written in a personal style, as though it follows the author's own evolution from work primarily in craniometry and variation in physical traits to his realization of the importance of population genetics. This evolution is particularly obvious in Chapter 9, about Relethford's work on the Irish, a chapter that I feel adds little to the more general tone of the rest of the book.

M ost of the book is conventionally organized into the general issues of phylogeny construction (Chapter 2), a long chapter on fossils and interpretation of mitochondrial DNA variation (Chapter 3 ), the problem of the N eandertals (Chapter 4), and interpretation of between-population and withinpopulation variation (Chapter 5). The second half of the book might be regarded as a collection of case histories: the Americas (Chapter 6), the spread of farming (Chapter 7), the peopling of Polynesia (Chapter 8), the Irish (Chapter 9), and special hot topics, mostly about admixture, for example African-Americans, Jews in the Diaspora, and Thomas Jefferson's $Y$ chromosome (Chapter 10).

Relethford's style is to avoid technical details and to use numerical examples to explain difficult concepts. This works well in the case of admixture but is less successful for the notion of coalescence. The descriptions and interpretations of the data, although admirably simple, are rarely original. Chapter 7 , for example, on the spread of farming, is built entirely around the ideas of Ammerman and Cavalli-Sforza. Indeed, much of the book's material can be found in two popular treatments by Cavalli-Sforza, The Great Human Diasporas: The $\mathrm{H}$ istory of Diversity and Evolution and Genes, Peoples, and Languages.

Although most human evolutionists today fall into the African replacement school, which holds that modern humans left Africa 100,000-150,000 years ago and soon replaced the hominid groups that might have existed in Asia or Europe at that time, there is a pocket of researchers, mostly connected with Milford Wolpoff and the University of Michigan, who believe that those resident populations were not replaced but made important contributions to the lineage of modern humans. This is called the multiregional hypothesis. Relethford devotes much of Chapter 3 to sitting on the fence between these rival schools, a fence he calls "mostly out of Africa". This is unfortunate because he justifies his opinions with the quantitative analyses of DNA polymorphisms made by Alan Templeton, a researcher with strong Michigan connections. Templeton's justification of Wolpoff's multiregional view is based on a statistical method that Templeton calls "nested cladistic analysis". Relethford accepts the findings from this analysis uncritically, which is regrettable because recent extensive computer-based tests have shown that this analysis is seriously flawed (Mol Ecol 11: 2623-2635 (2002)). Although Relethford can be criticized for leaning too far towards the multiregional position, he might be excused because the issue requires a technical resolution that is not easily accessible to the non-specialist.

The same problem arises in the discussion of the number of ancestors whose descendants grew in number to form the modern human population. Relethford's estimate of 20,000-30,000 derives from Harpending and colleagues' special model of demographic history (Curr Anthropol 34: 484-496 (1993)), which is not described in the text and is at best an extreme oversimplification of what might have been the actual demography. However, it does leave the reader with the feeling that the number has greater mathematical credibility than it actually deserves. In fact, recent estimates of the size of the group that left Africa and expanded to found the modern human population are perhaps one-tenth of this (see, for example, Genetics 161: 447-459 (2002); Am J Hum Genet 72: 1171-1186 (2003)).

Although these criticisms of the material in Chapter 3 are important, they do not detract from the overall value of this highly readable book that admirably conveys the excitement involved in the interdisciplinary detective work necessary to elucidate human evolution.

\section{MarcusW. Feldman isin the D epartment of Biological Sciencesat Stanford University, Stanford, California, USA.}

\section{E-mail: marc@charles.stanford.edu}

doi:10.1038/sj.embor.7400075 